\title{
Biological controls investigated to aid management of olive fruit fly in California
}

\author{
by Kent M. Daane, Marshall W. Johnson, \\ Charles H. Pickett, Karen R. Sime, Xin-Geng \\ Wang, Hannah Nadel, John W. Andrews Jr. and \\ Kim A. Hoelmer
}

The widespread and rapid establishment of the olive fruit fly in California required immediate changes in integrated pest management (IPM) programs for olives. After finding that resident natural enemies did not provide adequate control, researchers began a worldwide search for parasitoids, with exploration in the Republic of South Africa, Namibia, India, China and other countries. Parasitoids were shipped to California, and most were studied in quarantine to determine the best species for release. Two parasitoid species - Psyttalia lounsburyi and Psyttalia humilis - are now being released throughout the state's olive-growing regions, and researchers are studying their effectiveness.

The olive fruit fly was first found in 1 Southern California in 1998 (Rice et al. 2003). Facilitated by longevity and the adults' ability to fly long distances, the fly dispersed rapidly throughout the state. There was little opportunity to attempt a statewide eradication program, so current research efforts emphasize long-term management practices. Biological control may be a part of this program (Daane and Johnson 2010).

How might natural enemies contribute to the control of olive fruit fly (Bactrocera oleae [Rossi])? Commercial orchards now rely upon a broadspectrum insecticide combined with a highly attractive bait (Johnson et al. 2006). The effectiveness of insecticidebased programs is, however, limited by the abundance of roadside and residential olive trees in California,
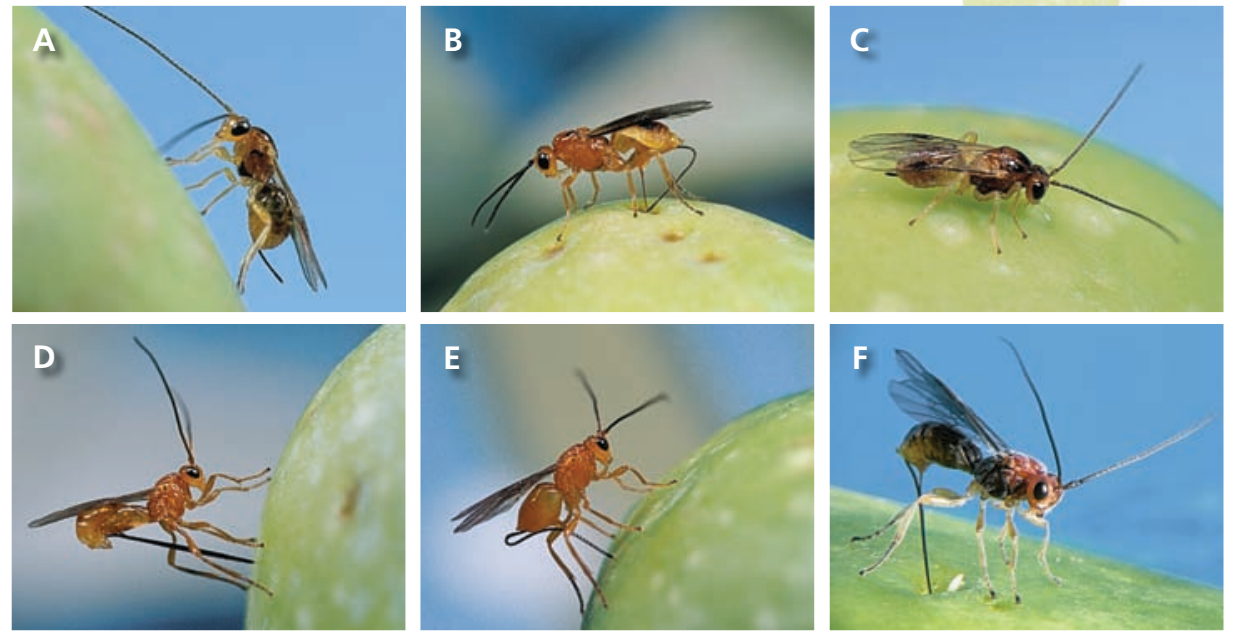

Parasitoids imported into California for quarantine studies include braconid parasitoids reared from wild olive fruit fly, (A) Psyttalia lounsburyi, (B) Bracon celer and (C) Utetes africanus, as well as braconid parasitoids reared on other fruit fly species, including (D) Diachasmimorpha longicaudata, (E) D. kraussii and (F) Fopius arisanus.

which serve as reservoirs and contribute to the fly's reinvasion of treated orchards (Collier and Van Steenwyk 2003). Classical biological control - the importation of natural enemies from the pest's home range - offers the best opportunity to economically suppress olive fruit fly populations in these situations. We review ongoing efforts in California to (1) document the natural enemies of olive fruit fly already present, (2) search for and import novel natural enemies from other countries and (3) determine the effectiveness and limitations of these natural enemy species. To date, California scientists have received approval from the U.S. Department of Agriculture's Animal and Plant Health Inspection Service (USDA-APHIS) for the release of several parasitoid species, and permits are pending for two others (see page 26).

\section{Natural enemies in California}

Although the olive fruit fly is native to Africa and Asia (Nardi et al. 2005), some North American predators and parasitoids may attack it. Insect predators such as lady beetles and lacewings are found in olive orchards, but because the fly's eggs are embedded underneath the fruit's epidermis and the larvae feed deep inside the fruit (Tzanakakis 2006), the immature stages are protected from most generalist predators.

Before the larva pupates, it creates a thin window on the fruit surface through which it may be exposed to predators. If the fruit is still firm, the larva will often pupate inside. However, upon fruit maturation most fly larvae leave the older fruit, especially in the late summer and fall, and drop to the ground to pupate in the soil beneath the tree (Tzanakakis 2006). Orsini et al. (2007) placed fly puparia (which enclose the fly pupa) on the ground in olive orchards and used different barriers around each to distinguish mortality levels due to abiotic (e.g., climate) and biotic (e.g., predators) factors. In an August trial, olive fruit fly exposed to predators was reduced by about $60 \%$ compared to other treatments (fig. 1). Ants (e.g., Formica species) were the most abundant predators on the ground and were observed carrying and killing olive fruit fly pupae. Predation rates vary among orchards, depending on factors such as the species and densities of predators present and the soil depth at which fly pupae are located. European studies similarly indicate that arthropods can inflict substantial mortality on olive fruit fly pupae (Daane and Johnson 2010; Tzanakakis 2006). 
A California-resident parasitoid has also been found attacking olive fruit fly. The parasitoid is similar to the European Pteromalus myopitae (Graham) (Hymenoptera: Pteromalidae), hence it is currently referred to as Pteromalus species near myopitae (P. sp. nr. myopitae). It has been reared from olive fruit fly collected primarily in coastal counties from San Luis Obispo to San Diego, although it has also been collected in Alameda, Butte, Fresno, Solano and Yolo counties. This parasitoid is solitary (one per fly larva) and feeds externally on third-instar olive fruit fly. An olive fruit fly survey in San Luis Obispo County reported an average parasitism level of $2.98 \%$ by P. sp. nr. myopitae (Kapaun et al. 2010). Parasitism levels varied considerably, ranging from $0 \%$ to $33 \%$ (based on collections of 100 infested fruit per week) with activity highest in August and September. Because P. sp. nr. myopitae has never been reported elsewhere, it is likely a North American parasitoid of native fruit flies; it opportunistically parasitizes olive fruit fly but has never been collected on any native fruit fly species despite numerous surveys.

\section{Foreign exploration}

Imported material. Resident natural enemies do not adequately suppress olive fruit fly populations below damaging levels. For this reason, California researchers began seeking natural enemies abroad in 2003 . The

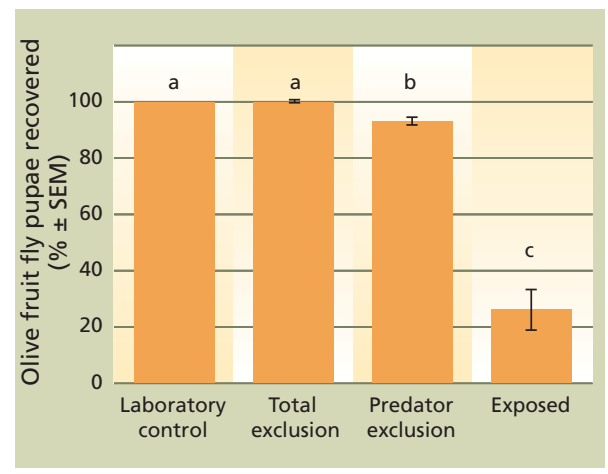

Fig. 1. Mean percentage ( \pm SEM) of olive fruit fly pupae recovered after 4 days (August 2005) when held in laboratory control, and placed in an olive orchard where treatments were "total exclusion" of all natural enemies; "predator exclusion," preventing walking predators from reaching pupae; and "exposed," allowing both flying and walking natural enemies access to pupae. Different letters above each bar indicate significant differences (Tukey's HSD test, $P<0.05$ ) (Orsini et al. 2007).
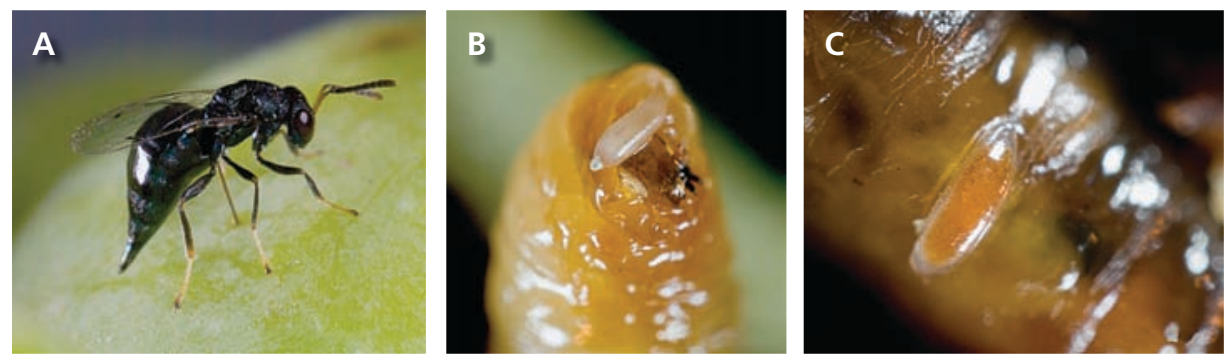

Pteromalus species near myopitae is resident to California and has been reared from olive fruit fly collected primarily in coastal counties. The adult (A) oviposits onto second- or third-instar fly larvae, placing an egg (B) on the outside of the larva, where the parasitoid larva (C) develops as a solitary, external parasitoid.

search started in Africa, where olive fruit fly probably originated and there is a rich diversity of fruit fly parasitoids. Olive fruit fly parasitoids were reported in Africa as early as 1912 by the renowned Italian entomologist Filippo Silvestri during surveys for parasitoids of Mediterranean fruit fly (Medfly) (Ceratitis capitata [Wiedemann]) (Wharton 1989).

Members of the USDA Agricultural Research Service's European Biological Control Laboratory, the California Department of Food and Agriculture, UC researchers and cooperators explored the Republic of South Africa, Namibia, Kenya, La Réunion (an island east of Madagascar), the Canary Islands, Morocco, Pakistan, India and China. Collections for "specialists" (i.e., natural enemies that primarily attack one species) were made from wild olive fruit (Olea europaea ssp. cuspidata) from south to northeast Africa, and from southwest Asia to central China. The parasitoids reared from olive fruit fly included Psyttalia lounsburyi (Silvestri), Psyttalia concolor (Szépligeti), Psyttalia humilis (Szépligeti), Psyttalia ponerophaga (Silvestri), Utetes africanus (Silvestri) and Bracon celer Szépligeti.

The greatest yield of parasitoids came from collections made in South Africa, Namibia and Kenya (table 1). The most common species were $U$. africanus, P. lounsburyi and P. humilis (table 1). The highest levels of parasitism were found in Kenya collections where $P$. lounsburyi and $U$. africanus together parasitized more than $57 \%$ of collected flies. The next highest parasitism levels were in collections from Pakistan (27.7\% parasitism by P. ponerophaga) and Republic of South Africa (27.8\% to $68.0 \%$ parasitism by P. humilis, P. lounsburyi, $B$. celer and $U$. africanus during 3 years of collections). Although P. concolor was the only olive fruit fly parasitoid found in Morocco and the Canary Islands, parasitism rates were limited to $14.6 \%$ and $2.3 \%$, respectively. Similarly, in the Republic of South Africa, P. humilis accounted for less than $4 \%$ of parasitism. However, in Namibia P. humilis was the dominant parasitoid and attained parasitism levels from $18.1 \%$ to $35.1 \%$. In China, few olive fruit flies were collected, although one (unidentified) Diachasmimorpha species was obtained, and in India no olive fruit were found on wild olive trees during the 2006 and 2007 explorations (Alan Kirk, personal communication).

Numerous fruit fly parasitoids are known to attack other flies in the genus Bactrocera. A few of these more "generalist" parasitoids (i.e., natural enemies that attack numerous species) were also imported to California. These were Fopius arisanus (Sonan), Diachasmimorpha kraussii (Fullaway) and D. longicaudata (Ashmead). All were supplied by Russell Messing at University of Hawaii, where they had been reared on Medfly. Similarly, colonies of $P$. humilis maintained on Medfly in Guatemala were sent to California, supplied by Pedro Rendon of the USDA APHIS Plant Protection and Quarantine program (Yokoyama et al. 2008, 2010).

Reported efforts. A parasitoid's performance in other regions provides insights for researchers when determining which natural enemy species should be released. P. lounsburyi was identified nearly 100 years ago as an olive fruit fly parasitoid and is often reported as the most effective natural enemy in wild olives of southern Africa (Copeland et al. 2004). P. ponerophaga has a similar long association with olive fruit fly and is the only olive fruit fly specialist 
known from Pakistan (Wharton 1989). However, no systematic effort has been made to include these parasitoids in European biological control (Wharton 1989), presumably because they have been difficult to import and rear.

We found no reports of concerted efforts to import or manipulate $U$. africanus for biological control, although in some South African surveys it is an abundant olive fruit fly parasitoid in wild olives (Hancock 1989). Similarly, B. celer is often the most commonly reported parasitoid attacking olive fruit fly in commercial and wild olives in South Africa (Neuenschwander 1982), where it achieved parasitism rates as high as $87 \%$. However, small-scale attempts to rear and/or release B. celer in Europe have been unsuccessful (Wharton 1989).

Instead, biological control of olive fruit fly has focused on members of the $P$. concolor species complex, which includes $P$. concolor from northern Africa and P. humilis from sub-Saharan Africa, especially after an efficient massrearing method was developed in the 1950s using Medfly reared on an artificial diet (Daane and Johnson 2010). However, P. concolor has not provided adequate or consistent olive fruit fly control in Europe and, where it has established, repeated mass releases are required to boost parasitism rates (Copeland et al. 2004). Nonetheless, we consider $P$. concolor and $P$. humilis to be important to screen for use in California biological control. Their native range spans much of northern and eastern Africa (Wharton and Gilstrap 1983) and, given the diversity of habitats and climates encompassed, they likely comprise several biotypes, or even new species or genetically differentiated populations (Rugman-Jones et al. 2009), some of which may be better suited to control olive fruit fly in California (Yokoyama et al. 2010).

F. arisanus is well known as a generalist parasitoid of fruit-infesting tephritids. Native to Southeast Asia, it was introduced to the Hawaiian Islands in the 1940s and provided excellent control of Oriental fruit fly (Bactrocera dorsalis [Hendel]). It now also contributes to Medfly control (Wang, Messing, Bautista, et al. 2003). Following the success in Hawaii, F. arisanus was introduced widely to control these and other tephritid pests in Australia, Central America, various Pacific and Indian Ocean islands, and the Mediterranean Basin, though not all of these introductions have been as effective. The few attempts to establish F. arisanus on olive fruit fly in Europe were unsuccessful. One study reported that F. arisanus failed to reproduce on olive fruit fly in field cages (Neuenschwander et al. 1983); however, more recent laboratory work has confirmed that F. arisanus can reproduce on olive fruit fly (Calvitti et al. 2002; Sime et al. 2008).

D. longicaudata, a native of Southeast Asia (Wharton 1989), attacks a relatively wide range of tephritid flies, including Medfly, Oriental fruit fly, Caribbean fruit fly (Anastrepha suspensa [Loew]) and Mexican fruit fly (A. ludens [Loew]) (Wang and Messing 2004). It has been used widely for biological control. One attempt was made to rear and release it against olive fruit fly in Greece, but it did not become established (Daane and
Johnson 2010). Diachasmimorpha kraussii is native to Australia, attacks a range of Bactrocera species and has been released in Hawaii to control Medfly (BokononGanta et al. 2007); we have found no reports of its use against olive fruit fly, but it has been reported attacking olive fruit fly in Israel (C.H. Pickett, personal communication).

\section{Quarantine nontarget studies}

Before exotic natural enemies are released in California, quarantine studies are conducted to determine whether or not they will attack insect species other than the intended target (Hoelmer and Kirk 2005). There are more than 140 tephritids in California (Foote et al. 1993), including some endemic species and others that were brought into the state for the biological control of weeds. Rather than test all of these species, researchers assess parasitoid responses to fruit fly species found in the three common habitats of fruit fly larvae fruits, flower heads and stem galls - to explore their tendency to specialize on certain host habitats. Tested species are selected to maximize both practicality (ease of locating and/or rearing hosts) and potential for host acceptance (resemblance of infested plant structure to olives in shape or size). Therefore, most

\begin{tabular}{lcccccccccc}
\multicolumn{1}{c}{ TABLE 1. Fruit fly and parasitoids reared from field-collected wild olives for importation } \\
into California, 2003-2007
\end{tabular}

* Percentages of adult olive fruit fly and parasitoids reared are shown; does not include gall-formers or "unknown" parasitoid species that may have been reared from galls, from other fruit fly species or as hyperparasitoids on primary parasitoids of olive fruit fly. 
of the imported parasitoids were either sent directly to the UC Berkeley quarantine facility, or to the collaborating laboratory in France and then to the UC Berkeley facility.

Olive fruit fly belongs to the tephritid subfamily Dacinae, which is not native to North America. California's native and introduced fruit fly species fall into two other subfamilies, Trypetinae and Tephritinae (Foote et al. 1993). For a nontarget, fruit-feeding Trypetinae, researchers selected the native black cherry fly (Rhagoletis fausta [Osten Sacken]), which infests fruit of bitter cherry. For a flower-head feeder, they selected Chaetorellia succinea (Costa), an imported Tephritinae used to control yellow starthistle (Centaurea soltitialis L.). For a gall-former, researchers selected another Tephritinae biological control agent, Parafreutreta regalis (Munro), which forms stem galls in Cape ivy. The testing of C. succinea and $P$. regalis addressed the risk posed to beneficial species by the candidate parasitoids. Unless stated otherwise, these three species were common to all UC Berkeley quarantine studies; other nontarget fruit flies were tested when available.

There was some variation in the materials and methods used to test the different species, but procedures were generally as described by Daane et al. (2008). Briefly, researchers used small cages (about 12 square inches) to isolate female parasitoids with either target (olive fruit fly) or nontarget hosts for 48 hours in a no-choice test. Target and individual nontarget species were then placed together for a choice test for the next 48 hours. The number of searching events (i.e., parasitoids on the host plant) and probing events (i.e., parasitoids inserting their ovipositor to place an egg into the fruit, flower head or gall) were recorded during discrete observation periods. Afterward, the host material was isolated and held for parasitoid or fly emergence.

\section{Parasitoids and olive fruit fly}

P. lounsburyi. P. lounsburyi was the only parasitoid tested that probed only into infested olives and reproduced solely on olive fruit fly (table 2). That $P$. lounsburyi is relatively specialized on olive fruit fly is supported by the fact that it had been reared only from olive fruit fly in decades of field collections of African fruit flies (Copeland et al. 2004; Wharton et al. 2000). In addition, its geographic range is entirely contained within that of olive fruit fly.

$\boldsymbol{P}$. ponerophaga. It has been suggested that $P$. ponerophaga specializes on olive fruit fly because the parasitoid has only been reported from this species (Sime et al. 2007). Quarantinescreening studies of nontarget impacts

TABLE 2. Host-specificity trials - searching, probing and reproduction by imported parasitoids on olive fruit fly and nontarget fruit fly species

\begin{tabular}{|c|c|c|c|c|c|c|c|}
\hline Parasitoids* & $\begin{array}{c}\text { Olive } \\
\text { fruit fly }\end{array}$ & $\begin{array}{c}\text { Cherry } \\
\text { fly }\end{array}$ & $\begin{array}{c}\text { Apple } \\
\text { maggot }\end{array}$ & $\begin{array}{l}\text { Cape } \\
\text { ivy fly }\end{array}$ & $\begin{array}{c}\text { Yellow } \\
\text { starthistle } \\
\text { fly }\end{array}$ & $\begin{array}{l}\text { Currant } \\
\text { fly }\end{array}$ & Reference \\
\hline Psyttalia concolor (Italy) & S/P/RT & $\mathrm{S} / \mathrm{P}$ & $\mathrm{S} / \mathrm{P}$ & S/P/R & $\mathrm{S} / \mathrm{P}$ & $\mathrm{NI}$ & Unpublished data \\
\hline Psyttalia humilis (Kenya) & S/P/R & $\mathrm{S} / \mathrm{P}$ & $S / P$ & S/P/R & $\mathrm{NI}$ & $\mathrm{S}$ & Unpublished data \\
\hline Psyttalia humilis (Namibia) & S/P/R & - & - & S/P/R & $\mathrm{NI}$ & - & Unpublished data \\
\hline Psyttalia "unknown sp. A" & S/P/R & $S / R$ & $\mathrm{NI}$ & S/P/R & $\mathrm{NI}$ & $\mathrm{NI}$ & Unpublished data \\
\hline Psyttalia ponerophaga & S/P/R & - & - & $\mathrm{S} / \mathrm{P} / \mathrm{R}$ & $\mathrm{NI}$ & - & Unpublished data \\
\hline Psyttalia lounsburyi & $\mathrm{S} / \mathrm{P} / \mathrm{R}$ & $\mathrm{NI}$ & $\mathrm{NI}$ & $S$ & $\mathrm{NI}$ & $\mathrm{NI}$ & Daane et al. 2008 \\
\hline $\begin{array}{l}\text { Diachasmimorpha } \\
\text { longicaudata }\end{array}$ & $\mathrm{S} / \mathrm{P} / \mathrm{R}$ & $\mathrm{S} / \mathrm{P} / \mathrm{R}$ & $\mathrm{S} / \mathrm{P}$ & $\mathrm{S} / \mathrm{P} / \mathrm{R}$ & $\mathrm{NI}$ & $\mathrm{NI}$ & Unpublished data \\
\hline Diachasmimorpha kraussii & $\mathrm{S} / \mathrm{P} / \mathrm{R}$ & $\mathrm{S} / \mathrm{P} / \mathrm{R}$ & $\mathrm{S}$ & $\mathrm{S} / \mathrm{P} / \mathrm{R}$ & $\mathrm{S} / \mathrm{P} / \mathrm{R}$ & $\mathrm{S} / \mathrm{P}$ & Unpublished data \\
\hline Bracon celer & $\mathrm{S} / \mathrm{P} / \mathrm{R}$ & $\mathrm{S} / \mathrm{P}$ & $\mathrm{NI}$ & $\mathrm{S} / \mathrm{P} / \mathrm{R}$ & $\mathrm{S} / \mathrm{P}$ & $\mathrm{NI}$ & Nadel et al. 2009 \\
\hline Utetes africanus & $\mathrm{R}$ & $\mathrm{NI}$ & - & $\mathrm{NI}$ & $\mathrm{NI}$ & - & Unpublished data \\
\hline Fopius arisanus & S/P/R & - & - & $\mathrm{NI}$ & $\mathrm{NI}$ & - & Sime et al. 2008 \\
\hline
\end{tabular}

* Target host was olive fruit fly; nontarget hosts were cherry fly (Rhagoletis fausta [Osten Sacken]), apple maggot (Rhagoletis pomonella [Walsh]), Cape ivy fly (Parafreutreta regalis [Munro]), yellow starthistle fly (Chaetorellia succinea [Costa]) and currant fly (Euphranta canadensis [Loew]).

† $\mathrm{S}=$ host plant searched by parasitoid; $\mathrm{P}=$ host plant probed by parasitoid; $\mathrm{R}=$ parasitoid successfully reproduced in host; $\mathrm{NI}=$ parasitoid showed no interest in host plant or host during observation period; $-=$ not tested.

were limited to the weed biologicalcontrol agents $-C$. succinea (yellow starthistle fly) and P. regalis (Cape ivy fly) - and no fruit-infesting fly species were tested. In no-choice tests, $P$. ponerophaga adults probed into galls on Cape ivy and produced parasitoid offspring from this nontarget host, but did not probe or reproduce in yellow starthistle (table 2).

$P$. concolor and P. humilis. P. concolor should be viewed as a "species complex," as previously mentioned. While similar, there may be biological differences that influence their affectiveness in California. For example, researchers found that even P. humilis colonies from different locations had slightly different levels of host specificity (table 2). However, P. concolor and P. humilis populations tested were able to reproduce on nontarget Cape ivy fly. In other laboratory studies, $P$. concolor was similarly reared from numerous fruit fly species (Wharton and Gilstrap 1983). However, small-cage trials are artificial, and olive fruit fly and Medfly are the primary hosts of P. concolor and P. humilis in their native African range (Copeland et al. 2004; Wharton et al. 2000).

B. celer. B. celer also attacked and reproduced on Cape ivy fly, but surprisingly did not reproduce on the black cherry fly, the fruit-infesting fly tested with this species (table 2). However, B. celer did probe on host materials for all fruit flies presented except currant fly. To date, B. celer has been reported only as a parasitoid of olive fruit fly and Medfly in field surveys (Wharton et al. 2000), with an additional, unconfirmed record on Ceratitis nigra Graham.

U. africanus. One of the most commonly recovered species in the South African collections, $U$. africanus was difficult to rear in quarantine. It reproduced on olive fruit fly, as expected, but this parasitoid was never observed to show any interest (by searching or probing) in either the target or nontarget host plants during tests (table 2). The literature indicates that $U$. africanus has been reared from olive fruit fly, Medfly, Oriental fruit fly, coffee fruit fly (Trirhithrum coffeae Bezzi) and natal fly (Ceratitis rosa Karsch) (Wharton and Gilstrap 1983). 
Diachasmimorpha species. D. longicaudata and D. krausii were the most aggressive of the quarantine-screened parasitoids, probing nearly all host material presented and producing offspring from nontarget, fruit-infesting species as well as the beneficial species (table 2). This result was not surprising because in total they have been reared from more than 20 fruit fly species (Wharton and Gilstrap 1983).

F. arisanus. While F. arisanus is considered more of a generalist, it is not attracted to either $C$. succinea eggs on yellow starthistle buds, or $P$. regalis eggs in Cape ivy stems or the associated galls (table 2). These results are consistent with studies in Hawaii that show F. arisanus only attacking fruitfeeding tephritids (Wang, BokononGanta, et al. 2004). The host range in $F$. arisanus is probably constrained by its host-searching behavior: females are generally stimulated to search for host eggs by fruit odors; smooth, round fruit surfaces; and oviposition punctures left by flies (Wang and Messing 2003). Introducing F. arisanus to California still requires evidence that native, fruitfeeding Tephritidae are unlikely to be attacked. Sixteen tephritid species native to California feed in fruit (Foote et al. 1993), but at least eight are found at higher elevations where F. arisanus, a tropical species, is unlikely to flourish.

\section{Parasitoid biology studies}

Researchers studied the biology of imported natural enemies to help determine the best combination of species for release in California's climatically varied olive-growing regions. Parasitoid host-stage preference, development time, adult longevity and fecundity (offspring per female) were determined when colony numbers permitted these additional quarantine studies (table 3).

Host-stage preference. Newly infested olives were held for different lengths of time to create fruit with various olive fruit fly host "age categories" (i.e., different immature fly stages). These infested olives were placed with mated female parasitoids, and the amount of time the parasitoids searched and probed on the different age categories was recorded. After the exposure period, the olives were held to rear either adult parasitoids or flies. These experiments established that $P$. lounsburyi, P. ponerophaga, P. concolor, $P$. humilis, D. longicaudata and D. kraussii were internal parasitoids that preferred to oviposit into second- or third-instar olive fruit fly (table 3). B. celer is an external-feeding parasitoid that prefers late third-instar maggots. F. arisanus is an egg-larval parasitoid that inserts its eggs into olive fruit fly eggs, and the parasitoid completes its life cycle in the larval olive fruit fly. F. arisanus females may sometimes lay their eggs in firstinstar olive fruit fly.

Host-stage preference did not always correlate with reproductive success. This was most clearly seen in trials with P. lounsburyi, where adults spent more time probing olives with larger third-instar maggots (fig. 2A), but more offspring were produced from olives containing smaller second- and thirdinstar maggots (fig. 2B). Many parasitoids locate hidden hosts by detecting substrate vibrations. For example, adult P. concolor are thought to respond more
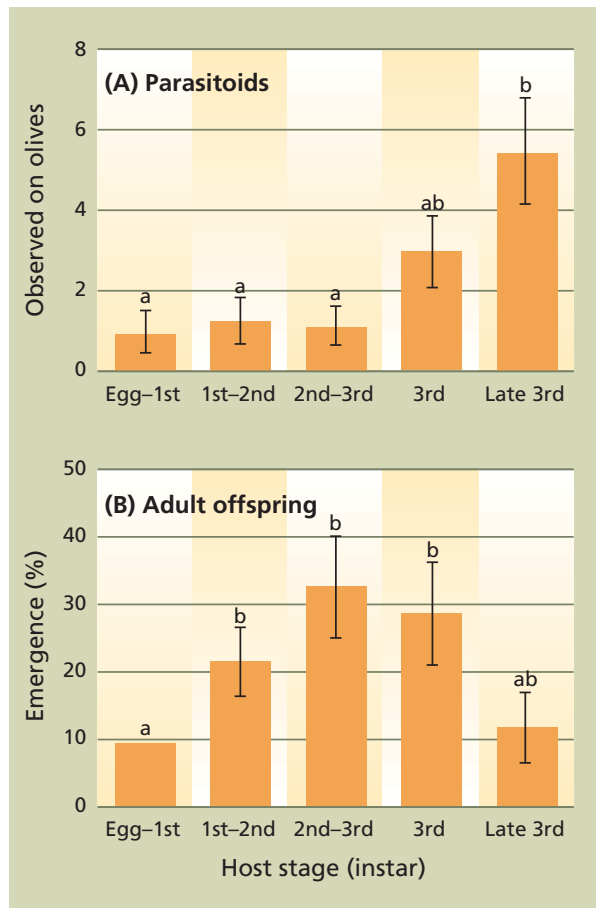

Fig. 2. Host-stage preference as mean percentage $( \pm$ SEM) of $(A)$ adult female Psyttalia lounsburyi on olives containing hosts of a given age category during timed observations and (B) P. lounsburyi offspring that emerged from different host-stage categories. Different letters above each bar indicate significant differences (one-way ANOVA, $P<0.05$ ) (Daane et al. 2008).

TABLE 3. Key biological parameters for parasitoids of olive fruit fly studied in UC Berkeley quarantine facility

\begin{tabular}{|c|c|c|c|c|}
\hline Host-stage preference & $\begin{array}{l}\text { Development time } \\
\text { (egg to adult) }\end{array}$ & Adult longevity & $\begin{array}{l}\text { Offspring per } \\
\text { female }\end{array}$ & Reference \\
\hline & \multicolumn{2}{|c|}{$\ldots \ldots \ldots \ldots \ldots$ days $\ldots \ldots \ldots \ldots \ldots$} & $n$ & \\
\hline Second to third instar & $20.5 \pm 1.5\left(77^{\circ} \mathrm{F}\right)$ & $36.2 \pm 4.9$ & $18.7 \pm 2.9$ & Sime et al. 2007 \\
\hline Second to third instar & - & $68.8 \pm 16.4$ & $22.5 \pm 5.1$ & Sime, Daane, Messing, et al. 2006 \\
\hline Second to third instar & $18.1 \pm 0.4\left(77^{\circ} \mathrm{F}\right)$ & $53.2 \pm 6.6$ & $48.8 \pm 8.5$ & Daane/Sime, unpublished data \\
\hline Third instar & $35.5 \pm 0.8\left(72^{\circ} \mathrm{F}\right)$ & $51.0 \pm 11.7$ & $9.7 \pm 7.2$ & Sime, Daane, Andrews et al. 2006 \\
\hline Second to third instar* & $20.5 \pm 1.0\left(75^{\circ} \mathrm{F}\right)$ & - & - & Daane/Sime, unpublished data \\
\hline Second to third instar & $20.8 \pm 0.9\left(77^{\circ} \mathrm{F}\right)$ & $59.2 \pm 5.0$ & $23.6 \pm 5.3$ & Sime, Daane, Nadel, et al. 2006 \\
\hline Second to third instar & $21.6 \pm 1.7\left(77^{\circ} \mathrm{F}\right)$ & $64.1 \pm 7.8$ & $22.7 \pm 5.5$ & Sime, Daane, Nadel, et al. 2006 \\
\hline
\end{tabular}

*Few replicates were completed with $U$. africanus, and only 10 adults were reared from olive fruit fly during the trial. 


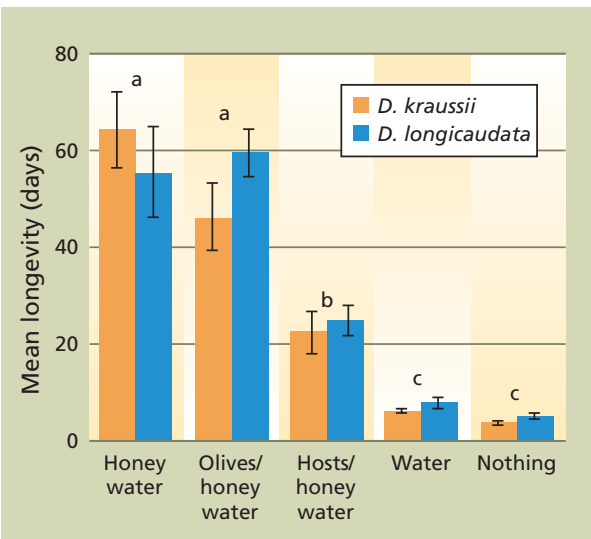

Fig. 3. Adult female Dichasmimorpha kraussii and $D$. longicaudata longevity given different food provisions. Different letters above each bar indicate significant treatment differences (Tukey's HSD test, $P<0.05$ ) (Sime, Daane, Nadel, et al. 2006).

strongly to the third than the second instar because the larger instar produces stronger or more frequent vibrations while feeding (Canale and Loni 2006). However, the third-instar olive fruit fly maggots feed deeper in olives and may be beyond the reach of the short P. lounsburyi ovipositor (less than 2 millimeters).

Development time. The egg-to-adult developmental rates of P. lounsburyi, P. ponerophaga, P. concolor, D. kraussii and D. longicaudata were relatively similar, about 22 days at constant temperatures near $77^{\circ} \mathrm{F}\left(25^{\circ} \mathrm{C}\right)$, while $B$. celer required nearly $40 \%$ more time (table 3 ). Olive fruit fly requires about 23 days at $77^{\circ} \mathrm{F}$ $\left(25^{\circ} \mathrm{C}\right)$, suggesting that (except for $B$. celer) these parasitoids could have generation times similar to olive fruit fly.

Adult longevity. When provisioned with water and honey, examined adult parasitoid species lived 36 to 78 days at temperatures around $77^{\circ} \mathrm{F}\left(25^{\circ} \mathrm{C}\right)$ (table 3). For all tested species, adults lived for less than 5 days without food, as shown for D. longicaudata and D. kraussii (fig. 3). For most species studied, there was also a reduction in longevity when adults were provided hosts in infested olives, suggesting that the parasitoids expended energy while handling hosts and that the parasitoids were able to distinguish host-infested olives from those lacking hosts.

Tolerances for high and low temperatures may be critical for parasitoid establishment in California because olive fruit fly infestations are found in both relatively cool coastal and hot inland areas, resulting in different seasonal development of the fly (Yokoyama et al. 2006). Overall patterns of adult longevity for all parasitoids tested showed a negative correlation with temperature, as shown for the Kenya and Italy colonies of $P$. humilis (fig. 4).

Lifetime fecundity. Researchers studied the parasitoids' reproductive potential by providing newly emerged and mated adult females with an overabundance of infested olives every 2 days (table 3). All species tested deposited most of their eggs during the first third or half of their life span (fig. 5). Surprisingly, the two specialists (P. lounsburyi and P. ponerophaga) had the lowest lifetime fecundity of the larval endoparasitoids, which develop inside the host (table 3). One hypothesis to explain these low fecundity rates concerns the relative lengths of their ovipositors (see below). Another explanation concerns the chemical cues used to orient to and identify host larvae and the host/plant complex. Domestic olives differ chemically from wild olives. These differences could disrupt the parasitoid's host-searching, hostidentification or ovipositional behaviors, or impede larval development.

Quarantine studies also reported low lifetime fecundity for B. celer, the external parasitoid, and F. arisanus, the egg-larval parasitoid (table 3 ), although in each case researchers suggest that experimental conditions may have negatively influenced natural egg deposition. In the UC Berkeley quarantine studies, researchers found up to $80 \%$ mortality of olive fruit fly eggs exposed to F. arisanus (Sime et al. 2008). Similar findings have previously been reported on olive fruit fly (Calvitti et al. 2002) and other hosts (Moretti and Calvitti 2003). Most likely this direct mortality results from the egg being repeatedly probed (i.e., stabbed) by the F. arisanus ovipositor. Olive fruit fly lays a single egg per fruit puncture, whereas the typical host of F. arisanus, the Oriental fruit fly, deposits up to 100 eggs per puncture (Ramadan et al. 1992). The tendency of F. arisanus to probe repeatedly within an oviposition puncture may be an evolutionary consequence of its use of this host. By comparison, more than 100 progeny can be obtained per female F. arisanus when reared on the Oriental fruit fly (Ramadan et al. 1992).

\section{Releasing natural enemies}

California researchers received USDA-APHIS approval for the release of P. lounsburyi and limited release of $P$. humilis; approval is pending for P. ponerophaga; and permits for the limited release of $F$. arisanus are being prepared. To date, $P$. lounsburyi has been released and recovered in field-cage studies, but has not yet been shown to overwinter. More work has been done with $P$. humilis, which is easier to rear, and levels of up to $60 \%$ parasitism have been reported from cage studies (Wang, Johnson, Daane, Yokoyama 2009; Yokoyama et al. 2008, 2010). However, as with $P$. lounsburyi, there is no clear evidence to date that $P$. humilis can

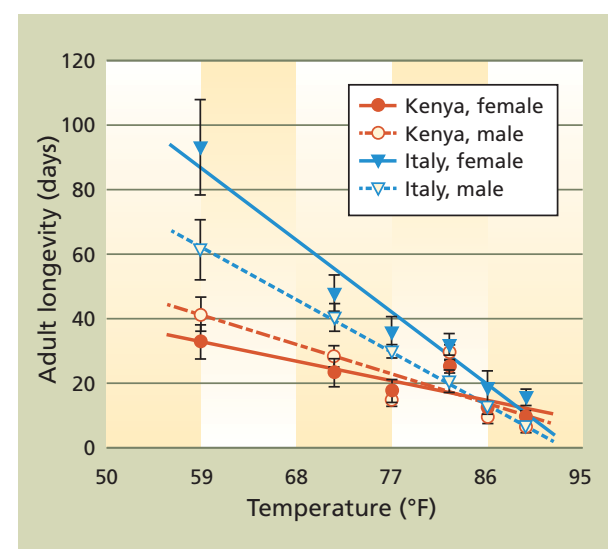

Fig. 4. Adult $P$. humilis longevity declined with increasing constant temperature for each gender and culture. Within each culture, no significant differences were found between female and male longevity at any temperature tested (Sime, Daane, Messing, et al. 2006).

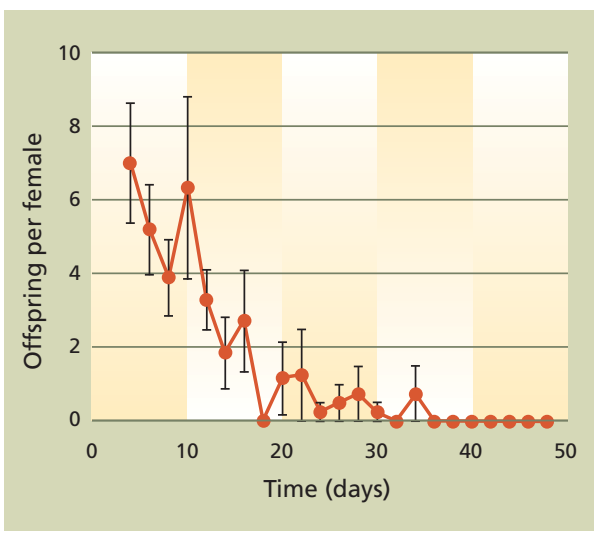

Fig. 5. Mean lifetime production of offspring ( \pm SEM) produced by $P$. humilis from a Kenyan culture (Sime, Daane, Messing, et al. 2006). 
establish and thrive without repeated augmentation.

There is a risk with the release of each natural enemy species that some nontarget species will be attacked, but the benefits often outweigh the risks (Hoddle 2004). Also, not all pest species are prime targets for classical biological control - there are potential problems with olive fruit fly and natural enemy biology that may limit the levels of control achieved.

Seasonal host availability. The olive fruit fly's survival is limited in regions with high or low temperature extremes (Wang, Johnson, Daane, Opp 2009). The fruit also may not be developed enough for olive fruit fly to survive early in the summer; young, hard fruit are not preferred for oviposition (Burrack and Zalom 2008). Moreover, olive fruit fly populations are scarce in some interior valley regions with high summer temperatures (Wang, Johnson, Daane, Nadel 2009) (see page 29). These facts suggest that parasitoid survival might also be difficult in some regions where their host, the olive fruit fly larvae, is scarce during some seasonal periods.

Wild versus domestic olives. The domestic olive is a distinct subspecies of wild olive, which has smaller fruit than most cultivated olives. As a result, fly maggots tunnel deeper inside the larger domestic olive. The ovipositors of specialized parasitoids (P. lounsburyi and $P$. ponerophaga) are too short to reach fly maggots feeding deep within the larger olives (Sime et al. 2007; Wang, Johnson, Daane, Yokoyama 2009; Wang, Nadel, Johnson, et al. 2009). The length of the ovipositor relative to the depth of the maggot within the fruit apparently limits the biocontrol agent's ability to successfully parasitize certain hosts, a problem that has been well documented for other fruit fly parasitoids (Sivinski et al. 2001). Therefore, African parasitoids of olive fruit fly may fail to successfully establish on fruit flies in fleshier European cultivars, because their short ovipositors are adapted for foraging in small, wild, African olives.

Surveys in wild and cultivated African olives provide support for this hypothesis. P. lounsburyi, U. africanus and $B$. celer are most commonly reared from wild olives (Copeland et al. 2004; Neuenschwander 1982), whereas
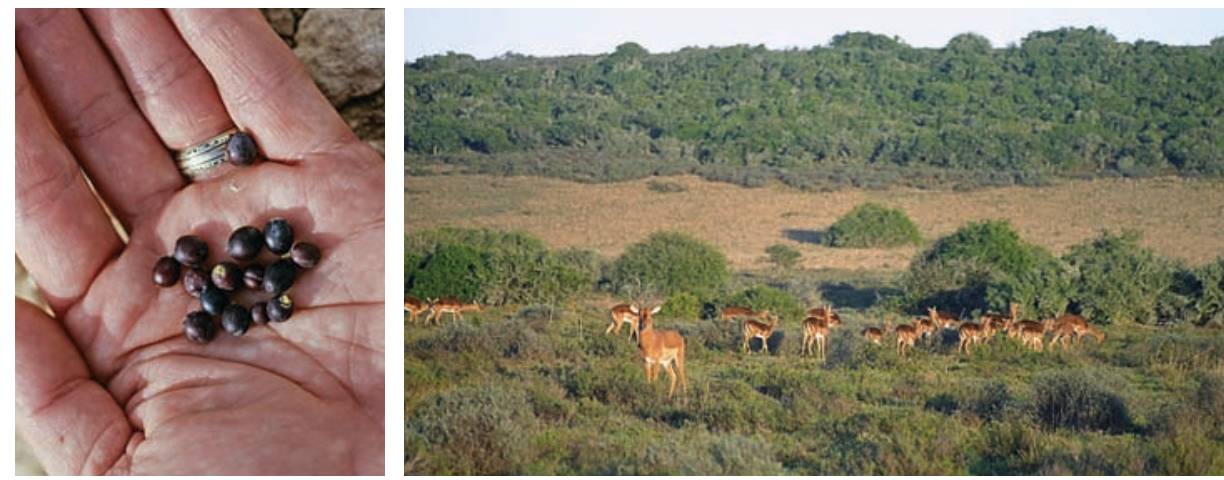

Ripe wild olives, left, collected in Africa, where olive fruit fly is considered to be native, are much smaller than the cultivated European varieties used throughout the world. Right, springbok and kudu graze among wild olive trees on a South Africa hillside. The African parasitoids that specialize on olive fruit fly found in small wild olives tend to have relatively short ovipositors that may not reach fly maggots deeper in the pulp of cultivated olives.

in cultivated olives, $B$. celer. with its much longer ovipositor, predominates, and the other species tend to be rare (Neuenschwander 1982). In the UC Berkeley quarantine studies, both $D$. longicaudata and D. kraussii reproduced well on cultivated olives, and these more generalist parasitoids have very long ovipositors (Sime, Daane, Messing, et al. 2006). Among the favorable characteristics of $F$. arisanus as a parasitoid of B. oleae are its relatively long ovipositor and the fact that it usually oviposits into eggs. Both features may help it circumvent the difficulties encountered by some larval parasitoids attacking

B. oleae in larger olive cultivars.

Natural enemy interactions. For best results natural enemies should coexist, but sometimes they interfere with each other. For example, the unexpected appearance of $P$. sp. nr. myopitae could potentially create a conflict with classical biological control efforts. Parasitoids that immobilize the host, including $P$. sp. nr. myopitae and B. celer, may have a competitive advantage over larval parasitoids that allow the host to continue to develop and grow after parasitoid oviposition, such as Psyttalia species. In quarantine experiments, researchers found that the egg-larval parasitoid F. arisanus prevailed in competition against two species of larval-pupal parasitoids, D. kraussii and P. concolor (Sime et al. 2008). The intrinsic competitive superiority of F. arisanus over larval-pupal parasitoids must be taken into consideration for its use in California.

Insecticides and biological control. Insecticide use affects biological control programs (Mills and Daane 2005).
Repeated sprays of GF-120 Naturalyte NF Fruit Fly Bait (Dow AgroSciences, Indianapolis, Ind.) are used to control olive fruit fly. Although this spinosad bait is classified as a reduced-risk material, its frequent use may disrupt biological control. Nadel et al. (2007) investigated the impact of GF-120 on a green lacewing (Chrysoperla carnea [Stephens]), and showed that ingestion clearly poses some risk to lacewing populations due to adult mortality and reduced fecundity. Laboratory studies indicated that several important braconid parasitoids of fruit flies - F. arisanus, Diachasmimorpha tryoni (Cameron) and Psyttalia fletcheri (Silvestri) - would not feed on fresh GF-120 residues, but when the insecticide was directly applied there were high mortality rates (Wang et al. 2005).

\section{Expectations in California}

Biological control can be a practical, safe and economically effective means of fruit fly control, and its importance continues to grow in regions where pesticide use is less desirable (e.g., sustainable agriculture) or more restricted (e.g., urban trees). The research programs that we describe provide background information on natural enemy biology, and identify specific natural enemies for importation and evaluation, and for possible release into California. Over the coming years, researchers will better understand the level of controls expected from imported natural enemies, and will improve IPM programs to integrate biological controls with the insecticides currently used in olive management. 
K.M. Daane is Cooperative Extension Specialist, Department of Environmental Science, Policy and Management, UC Berkeley; M.W. Johnson is Cooperative Extension Specialist and Entomologist, UC Riverside; C.H. Pickett is Research Entomologist, Biological Control Program, California Department of Food and Agriculture (CDFA); K.R. Sime is Assistant Professor, SUNY Oswego, N.Y.;

\section{References}

Bokonon-Ganta AH, McQuate GT, Messing RH. 2007. Natural establishment of a parasitoid complex on Bactrocera latifrons (Diptera: Tephritidae) in Hawaii. Biol Control 42:365-73.

Burrack HJ, Zalom FG. 2008. Olive fruit fly (Diptera: Tephritidae) ovipositional preference and larval performance in several commercially important olive varieties in California. J Econ Entomol 101:750-8.

Calvitti M, Antonelli M, Moretti R, Bautista RC. 2002. Oviposition response and development of the eggpupal parasitoid Fopius arisanus on Bactrocera oleae, a tephritid fruit fly pest of olive in the Mediterranean basin. Entomol Exp Appl 102:65-73.

Canale A, Loni A. 2006. Host location and acceptance in $P$. concolor: Role of host instar. Bull Insectol 59:7-10.

Collier T, Van Steenwyk R. 2003. Prospects for integrated control of olive fruit fly are promising in California. Cal Ag 57:28-30.

Copeland RS, White IN, Okumu M, et al. 2004. Insects associated with fruits of the Oleaceae (Asteridae, Lamiales) in Kenya, with special reference to the Tephritidae (Diptera). Bishop Mus Bull Entomol 12:135-64.

Daane KM, Johnson MW. 2010. Olive fruit fly: Managing an ancient pest in modern times. Annu Rev Entomol 55:155-69.

Daane KM, Sime KR, Wang, X-G, et al. 2008. Psyttalia lounsburyi (Hymenoptera: Braconidae), potential biological control agent for the olive fruit fly in California. Biol Control 44:79-89.

Foote RH, Blanc FL, Norrbom AL. 1993. Handbook of the Fruit Flies (Diptera: Tephritidae) of America North of Mexico. Cornell Univ Pr: Ithaca, NY. 571 p.

Hancock DL. 1989. Pest status: Southern Africa. In: Robinson A, Hooper G (eds.). Fruit Flies: Their Biology, Natural Enemies and Control (Vol 3A). Amsterdam: Elsevier. p 51-8.

Hoddle MS. 2004. Restoring balance: Using exotic species to control invasive exotic species. Conserv Biol 18:38-49.

Hoelmer KA, Kirk AA. 2005. Selecting arthropod biological control agents against arthropod pests: Can the science be improved to decrease the risk of releasing ineffective agents? Biol Control 34:255-64.

Johnson MW, Zalom FG, Van Steenwyk R, et al. 2006 Olive fruit fly management guidelines for 2006. UC Plant Prot Quart 16(3):1-7.

Kapaun T, Nadel H, Headrick D, Vredevoe L. 2010. Biology and parasitism rates of Pteromalus nr. myopitae (Hymenoptera: Pteromalidae), a newly discovered parasitoid of olive fruit fly Bactrocera oleae. Biol Control 53:76-85.

Mills NJ, Daane KM. 2005. Biological and cultural controls...Nonpesticide alternatives can suppress crop pests. Cal Ag 59(1):23-8.

Moretti R, Calvitti M. 2003. Mortality by parasitization in the association between the egg-pupal parasitoid Fopius arisanus and Ceratitis capitata. Biocontrol 48:275-91.
X.-G. Wang is Associate Specialist, Department of Environmental Science, Policy and Management, UC Berkeley; H. Nadel is Supervisory Entomologist, U.S. Department of Agriculture (USDA), Animal and Plant Health Inspection Service, Plant Protection and Quarantine program, Buzzards Bay, MA; J.W. Andrews Jr. was Quarantine Manager, College of Natural Resources, UC Berkeley; and K.A. Hoelmer is Research Entomologist and
Director, USDA Agricultural Research Service, European Biological Control Laboratory, Montpellier France.

We thank CDFA for funding this review; and the California Olive Committee, CDFA Biological Control Program (in collaboration with USDA) and USDA Cooperative State Research, Education, and Extension Service's Pest Management Alternatives Program for funding olive fruit fly research.
Nadel H, Daane KM, Hoelmer KA, et al. 2009. Nontarget host risk assessment of the idiobiont parasitoid Bracon celer (Hymenoptera: Braconidae) for biological control of olive fruit fly in California. Biocontrol Sci Technol 19:701-15.

Nadel H, Johnson MW, Gerik M, Daane KM. 2007. Ingestion of spinosad bait GF-120 and resulting impact on adult Chrysoperla carnea (Neuroptera: Chrysopidae). Biocontrol Sci Technol 17:995-1008.

Nardi F, Carapelli A, Dallai R, et al. 2005. Population structure and colonization history of the olive fruit fly, Bactrocera oleae (Diptera, Tephritidae). Mol Ecol 14:2729-38.

Neuenschwander P. 1982. Searching for parasitoids of Dacus oleae (Gmel.) (Dipt., Tephritidae) in South Africa. J Appl Entomol 94:509-22.

Neuenschwander P, Bigler F, Delucchi V, Michelakis SE. 1983. Natural enemies of preimaginal stages of Dacus oleae Gmel. (Dipt., Tephritidae) in Western Crete. I. Bionomics and phenologies. Bollettino Laboratorio Entomologia Agraria Filippo Silvestri 40:3-32.

Orsini MA, Daane KM, Sime KR, Nelson EH. 2007. Mortality of olive fruit fly pupae in California. Biocontrol Sci Technol 17:797-807.

Ramadan MM, Wong TTY, Beardsley JW. 1992. Reproductive behavior of Biosteres arisanus (Sonan) (Hymenoptera: Braconidae), an egg-larval parasitoid of the oriental fruit fly. Biol Control 2:28-34.

Rice R, Phillips P, Stewart-Leslie J, Sibbett G. 2003. Olive fruit fly populations measured in Central and Southern California. Cal Ag 57:122-7.

Rugman-Jones PF, Wharton R, van Noort T, Stouthamer R. 2009. Molecular differentiation of the Psyttalia concolor (Szépligeti) species complex (Hymenoptera: Braconidae) associated with olive fly, Bactrocera oleae (Rossi) (Diptera: Tephritidae), in Africa. Biol Control 49:17-26.

Sime KR, Daane KM, Andrews JW, et al. 2006. The biology of Bracon celer as a parasitoid of the olive fruit fly. Biocontrol 51:553-67.

Sime KR, Daane KM, Kirk A, et al. 2007. Psyttalia ponerophaga (Hymenoptera: Braconidae) as a potential biological control agent for the olive fruit fly in California. Bull Entomol Res 97:233-42.

Sime KR, Daane KM, Messing RH, Johnson MW. 2006. Comparison of two laboratory cultures of Psyttalia concolor (Hymenoptera: Braconidae), as a parasitoid of the olive fruit fly. Biol Control 39:248-55.

Sime KR, Daane KM, Nadel H, et al. 2006. Diachasmimorpha longicaudata and D. kraussii (Hymenoptera: Braconidae), potential parasitoids of the olive fruit fly. Biocontrol Sci Technol 16:169-79.

Sime KR, Daane KM, Wang X-G, et al. 2008. Evaluation of Fopius arisanus as a biological control agent for the olive fruit fly in California. Agr Forest Entomo 10:423-31.

Sivinski J, Vulinec K, Aluja M. 2001. Ovipositor length in a guild of parasitoids (Hymenoptera: Braconidae) attacking Anastrepha spp. fruit flies (Diptera: Tephritidae) in Southern Mexico. Ann Entomol Soc Am 94:886-95

Tzanakakis ME. 2006. Insects and Mites Feeding on Olive. Boston: Brill. 182 p.
Wang X-G, Bokonon-Ganta AH, Ramadan MM, Messing RH. 2004. Egg-larval opiine parasitoids (Hym., Braconidae) of tephritid fruit fly pests do not attack the flowerhead-feeder Trupanea dubautiae (Dip., Tephritidae). J Appl Entomol 128:716-22.

Wang X-G, Ekhlass J, McGraw BK, et al. 2005. Effects of spinosad-based fruit fly bait GF-120 on fruit fly and aphid parasitoids. Biol Control 35:155-62.

Wang X-G, Johnson MW, Daane KM, Nadel H. 2009. High summer temperatures affect the survival and reproduction of olive fruit fly (Diptera: Tephritidae). Env Entomol 38:1496-504.

Wang X-G, Johnson MW, Daane KM, Opp S. 2009. Combined effects of heat stress and food supply on flight performance of the olive fruit fly (Diptera: Tephritidae). Ann Entomol Soc Am 102:727-34.

Wang X-G, Johnson MW, Daane KM, Yokoyama VY. 2009. Larger olive fruit size reduces the efficiency of Psyttalia concolor, as a parasitoid of the olive fruit fly. Biol Control 49:45-51.

Wang X-G, Messing RH. 2003. Foraging behavior and patch time allocation by Fopius arisanus (Hymenoptera: Braconidae), an egg-larval parasitoid of tephritid fruit flies. J Insect Behav 16:593-612.

Wang X-G, Messing RH. 2004. Potential interactions among pupal and egg- or larval-pupal parasitoids of tephritid fruit fly. Env Entomol 33:1313-20.

Wang X-G, Messing RH, Bautista RC. 2003. Competitive superiority of early acting species: A case study of opiine fruit fly parasitoids. Biocontrol Sci Technol 13:391-402.

Wang X-G, Nadel H, Johnson MW, et al. 2009. Crop domestication relaxes both top-down and bottomup effects on a specialist herbivore. Basic Appl Ecol 10:216-27.

Wharton RA. 1989. Classical biological control of fruitinfesting Tephritidae. In: Robinson A, Hooper G. (eds.). Fruit Flies: Their Biology, Natural Enemies and Control (Vol 3B). Amsterdam: Elsevier. p 303-13.

Wharton RA, Gilstrap FE. 1983. Key to and status of opiine braconid (Hymenoptera) parasitoids used in biological control of Ceratitis and Dacus spp. (Diptera: Tephritidae). Ann Entomol Soc Am 76:721-42.

Wharton RA, Trostle MK, Messing RH, et al. 2000. Parasitoids of medfly, Ceratitis capitata, and related tephritids in Kenyan coffee: A predominantly koinobiont assemblage. Bull Entomol Res 90:517-26.

Yokoyama VY, Cáceres CE, Kuenen LPS, et al. 2010 Field performance and fitness of an olive fruit fly parasitoid, Psyttalia humilis (Hymenoptera: Braconidae), mass reared on irradiated Medfly. Biol Control 54:90-9.

Yokoyama VY, Miller GT, Stewart-Leslie J, et al. 2006. Olive fruit fly (Diptera: Tephritidae) populations in relation to region, trap type, season and availability of fruit. J Econ Entomol 99:2072-9.

Yokoyama VY, Rendón PA, Sivinski J. 2008. Psyttalia cf. concolor (Hymenoptera: Braconidae) for biological control of olive fruit fly (Diptera: Tephritidae) in California. Env Entomol 37:764-73. 